\title{
The positive psychology of recovery: a review
}

\begin{abstract}
Can Positive Psychology provide an adequate theory to understand and address addiction? This is the question addressed in this current review. Positive Psychology is far from merely a study about what is positive. It supports grappling with addiction from a stance of hope, optimism and growth. Using a literature review and numerous examples, this paper discusses Positive Psychology and addictions recovery. This review finds that Positive Psychology provides a compelling model for understanding and treating addiction. Positive Psychology seeks to build a life worth living, rather than merely avoiding substance use. Numerous practical Positive Psychology strategies are applied to addiction treatment. Lastly, the review also discusses a number of important gaps in the literature. It should be noted that for brevity, this review uses the abbreviation PP rather than Positive Psychology.
\end{abstract}

Keywords: psychology, addiction, substance use
Volume 3 Issue 3 - 2017

\author{
Sean M Swaby \\ City University of Seattle Edmonton, Canada
} Correspondence: Sean M Swaby, City University of Seattle
Edmonton, Alberta Campus, Canada,

Email smswaby@icloud.com

Received: July 29, 2016 | Published: May 01, 2017

\section{Introduction}

Lenninger ${ }^{1}$ Can Positive Psychology provide an adequate theory to understand and address addiction? PP is arguably a new theory, with a growing body of research. Over the past ten years, PP and the Recovery Movement have grown up next to each other with very little crossover research. ${ }^{2}$

Positive Psychology did not begin as an addiction theory, but is increasingly being applied to mental health and addiction studies. ${ }^{2,3}$ It takes a stance of "Recognizing that there is more to mental health than the absence of mental illness, positive psychology is dedicated to the rigorous scientific study of 'strengths, well being optional functioning'. ${ }^{2}$

This paper grew out of the author's teaching practice in a Master's degree Psychology of Addiction's course with City University of Seattle (Edmonton, Alberta Campus). The students in the course increasingly have an appetite for more positive, non-pathologizing approaches to addiction. The dominant theory in the field is the medical model, which seeks to diagnose, label, medicate and treat addiction. Many in the helping profession recognize that medical approaches have value, but tend to create stigma, solidify a problem mindset and treat with pills rather than psychosocial interventions that teach skills and re-engaging with real life. PP is different.

\section{Why positive psychology?}

The science of psychology has been far more successful on the negative than on the positive side. It has revealed to us much about man's shortcomings, his illness, his sins, but little about his potentialities, his virtues, his achievable aspirations, or his full psychological height. It is as if psychology has voluntarily restricted itself to only half its rightful jurisdiction, the darker, meaner self. Abraham Maslow as cited by Lopez \& Gallagher. ${ }^{4}$

PP makes the argument that human behavior exists along a spectrum of ill-health on the one side, and thriving and well-being on the other. ${ }^{2} \mathrm{PP}$ is beginning to invest research into applying positive interventions to the problems that people find themselves in. It needs to be highlighted that PP is not stating that the rest of the psychology "establishment" is negative, while PP is "positive." Rather, PP makes the case that is an adjunct to "psychology as usual".2
Seligman $^{5}$ argues that modern psychology fulfills only half of it's original vision: to cure mental illness, to make our lives more productive, and to fulfill, identify and nurture high talent. PP strives to expand our resources to enable people to learn to thrive, despite the challenges they face in their mental health, physical health or other areas of their lives.

PP strives to resolve problems indirectly rather than head on. "Instead of focusing on responding to problems, PP focuses on the need to identify the positive qualities that help individuals to not only overcome problems, but also to go forward and flourish". ${ }^{3}$ In this sense, PP is more of a strategic theory and brings about change by building up character.

\section{Research review}

Krentzman ${ }^{2}$ conducted a review of 9 PP studies that apply directly to addiction and recovery. She found that the literature, while not extensive, points to the benefits of a positive, resilient approach to addiction recovery. She notes that the recovery field is dominated by an illness or pathology framework, however, a recovery-oriented framework is flourishing within treatment programs. ${ }^{2}$ Her review highlighted the benefits from gratitude interventions for those with increasingly greater "disadvantages" (ie: physical illness, low positive effect, patterns of high self-criticism). ${ }^{2}$ The literature, she found, demonstrates that positive effect, optimism, hopefulness, emotional vitality, enjoyment of life predict favorable outcomes in cases of heart disease, stroke and general morality. ${ }^{2}$ Lastly, her review discussed ${ }^{2}$ substance use and positive psychology interventions work best with individuals who are more motivated, self selected, and who make the exercises part of their routine.

Akhtar \& Boniwell ${ }^{6}$ reported on a pilot group of a positive psychology recovery program for 10 adolescents. They discussed that positive interventions have promise in the reduction and prevention of depressive symptoms in young adolescents with elevated levels of behaviour problems. ${ }^{6}$ And inducing gratitude is demonstrated to increase sense of well being and overall satisfaction along with decreasing negative affect. ${ }^{6}$

Mohatt, Rasmus, Thomas, Allen, Hazel \& Marlat ${ }^{7}$ interviewed 57 participants who self-identified as being alcohol abstinent for five years, and with a history of problem drinking. The study found no 
single approach to recovery. While they were clear that the interviews did not demonstrate a unified model of change, the interviews highlight that strengths and resilience co-exist with even the most extensive substance use. Taken together, these aspects of resilience became the keys to recovery as they were practiced again and again through each attempt to change. Participants highlighted reflecting on consequences and the level of satisfaction with their lives, making intentional experiments with sobriety and learning from each relapse, and finally learning to rebuild a life outside of substance use, a theme common in PP.

Resilience is a core strength in PP. Alim et al., ${ }^{8}$ in a 2012 review for Alcohol Research ${ }^{8}$ found a range of psychosocial factors associated with resilience in the face of traumatic events. Optimism is associated with resilience despite experiencing stress-related disorders or addiction and their review found that regularly experiencing positive emotions is associated with resilience, and serve as a buffer against family conflict, parental or peer substance abuse.

Seligman ${ }^{5}$ describes that learning optimism, and disputation skills can reduce depression recidivism by $50 \% .^{5}$ Further, he describes how $45-50 \%$ of the effectiveness of treatments can be attributed to placebo effects which are defined as hope, belief, confidence in self/treatment/medical staff. In many cases $(50 \%$ of USDA studies on (approved) antidepressants), there was no difference between the placebo and the drug. ${ }^{9} \mathrm{He}$ cites an online survey of 1700 self selected participants who responded positively to having at least one traumatic event (torture, grave illness, death of a child, rape, imprisonment, etc.) also experienced a greater level of strengths. ${ }^{9}$ The more negative life events they experienced, their strengths also increased.

Herrenkohl ${ }^{10}$ completed a literature review of children who have experienced violence or aggression. This population may not directly experience addiction, but the effects from violence often lead to various forms of mental illness and even addiction. His study has compelling findings that relate to PP and addiction recovery. Herrenkoh ${ }^{10}$ found factors that predict resilient functioning include positive self-esteem, ego-resilience, personal agency, low reactivity, high sociability, maintaining supportive relationships and gaining access to prosocial mentors; both individual characteristics and environmental influences. ${ }^{10}$

As for weaknesses, Krentzman discusses a number of weaknesses of PP. ${ }^{2}$ She found that some PP studies have methodological and measurement weaknesses, while others have overstated research claims. PP is somewhat linked to the self-help, positive thinking movements which lacks any research backing. For some, PP may work to maintain the status quo, maintaining happiness as opposed to harnessing anger or activism to rise up and create social change. She also highlights some evidence that indicated that PP may work best for highly motivated individuals, self-selected, and who continue the exercises beyond the conclusion of the formal intervention. ${ }^{2}$ In addition, much of the PP research has been conducted among healthy college students or individuals surfing the web looking for PP exercises. ${ }^{2}$

\section{Addiction and positive psychology}

In PP, substance use is viewed as a habitual way of avoiding unpleasant emotions and states associated with stress. At least at the beginning, it is a pleasure-seeking activity. ${ }^{2}$ For many, what began as pleasure eventually leads to a self-described hell. The repetitive avoidance of emotions or problems through the use of a substance, or behaviour (ie: gambling, internet use, or work) develops a pattern of ineffective coping and a reduced emotional life, inflexible thinking, an increasingly pessimistic view of life, preoccupation with substance use rather than more important tasks or involvements, along with an avoidant coping style as opposed to an open/engaging approach). ${ }^{8}$

PP responds to substance use by working to build positive character strengths which will aid a person to address significant life issues. Krentzman ${ }^{2}$ succinctly states that addiction and recovery can be understood as an erosion and then rebuilding of character strengths. ${ }^{2}$ "Instead of focusing on responding to problems, PP focuses on the need to identify the positive qualities that help individuals to not only overcome problems, but also to go forward and flourish". 3

PP grapples with and acknowledges the depth of human suffering while not engaging in pathologizing. ${ }^{2}$ It utilizes "positive activity interventions" (PAIs) that are "relatively brief, self-administered, and non-stigmatizing exercises that promote positive feelings, positive thoughts, and/or positive behaviors, rather than directly aiming to fix negative or pathological feelings, thoughts, and behaviours". ${ }^{2}$

Recovery is not only about remission of symptoms but about building a larger, more expansive and satisfying life. As the author of this paper says to his clients, "Recovery is not about the drugs, it is about what you do when you stop using." Recovery is about finding and developing meaning and purpose and building personal goals and strengths that align with personal values. ${ }^{8}$

\section{Recovery is build around an}

Honest desire for help, onset of new hope, absence of desire to escape, facing facts with courage, developing new interests, rebirth of ideals, application of real values, confidence of employers, and the endpoint, where an 'enlightened and interesting way of life opens up the road ahead to higher levels than ever before. ${ }^{2}$

Krentzman $^{2}$ goes on to say that for many a sense of spirituality is a positive, life-affirming part of their recovery. Spirituality has a number of positive factors including altruistic behaviors, helping others in their recovery, and a focus on quality of life. ${ }^{2}$

PP views substance use not as a deficit that is in need of a cure, but as the need for greater capacities built around the substance use, in other areas of a person's life. It grapples honestly with pain, with struggle and with relapse, while holding to a strong belief in a person's ability to change and improve. PP works alongside other models that may involve diagnosis, and looks to build resources to both make and maintain the changes necessary to recover from whatever addiction a person encounters in their lives.

\section{Positive psychology and addiction: strategies to build a new life}

The solution to addiction is what is happening in the rest of a person's life. PP builds capacities and experiences that would address each of the areas of a person's life that are ineffectual, or less than optimal-functioning. For example: Positive psychology will build capacity for a more complete emotional experience and expression; increase positive, open coping; build/re-build a life that supports a move away from addiction (building a life worth living rather than merely trying to live without drugs or a particular addiction); increase flexible thinking and problem solving; identify and engage important experiences, tasks, projects, relationships, leading to the creation of 
a greater sense of purpose; grapple with tensions that one may not previously addressed, or that may need to be revisited; and recognize strengths that one has, and strengths one gained throughout the

Table I To achieve this aim, Positive Psychology provides a number of practical strategies experience with addiction: let no experience be wasted with regret, all experience can be our teacher.

\begin{tabular}{|c|c|c|}
\hline Intervention & Reference & Strategy \\
\hline \multirow[t]{4}{*}{$\begin{array}{l}\text { Highlight, broaden and build on strengths - This } \\
\text { strategy can be utilized to develop an identity } \\
\text { outside of substance use and it's associated } \\
\text { behaviours. }\end{array}$} & $\begin{array}{l}\text { Cohn \& } \\
\text { Fredrickson }\end{array}$ & $\begin{array}{l}\text { a. Engage in counting blessings and a daily effort to practice thankfulness. i.e.:Thin } \\
\text { of and state } 3 \text { things you are thankful for today. }\end{array}$ \\
\hline & & $\begin{array}{l}\text { b.Visualizing one's best life:When in a calm state, imagine your best possible self, } \\
\text { being specific in what you see, hear and even smell. Imagining yourself engaging } \\
\text { with your family, at work, in leisure and learning. }\end{array}$ \\
\hline & & $\begin{array}{l}\text { c. Identify and utilize "signature strengths",'2 or specific areas of your strengths } \\
\text { that you enjoy using at home, at work and in your other pursuits. }\end{array}$ \\
\hline & & $\begin{array}{l}\text { d.What do you do, and others you know do, to keep healthy, mentally, physically, } \\
\text { emotionally, spiritually? }\end{array}$ \\
\hline
\end{tabular}

Utilize catalyst questions-The questions listed with assessment and the building of insight. can be used in a counselling session and will aid

Ungar $^{13} \quad$ a.What would I need to know to grow up well here?

b. How do you describe people who grow up well here despite the many problems they face?

c. What does it mean to you, to your family, and to your community, when bad things happen?

d.What kinds of things are most challenging for you growing up here?

e.What do you do when you face difficulties in your life?

f.What does being healthy mean to you and others in your family and community?

g. Can you share with me a story about another child who grew up well in this community despite facing many challenges?

h. Can you share a story about how you have managed to overcome challenges you face personally, in your family, or outside your home in your community?

Akhtar \&

Boniwell $^{6}$

a. Teach disputation of negative beliefs or statements associated with adverse events; Reframing to generate alternative, more optimistic thinking. thinking while in recovery.

Enrich the emotional life-this serves a number of purposes, grounding in the present and helping a person to mature and grow in areas that have not fully developed due to addiction.

Develop a meaningful life
Krentzman $\mathrm{AR}^{2}$ a. Fully experiencing the moment, enjoying simple pleasures like rain, a bath, laughter, or the food we eat. It does not matter what the experience is, but taking even a few minutes to fully experience something can begin to transform our emotional experience. ${ }^{2}$

b. Daily gratitude practice-Recounting three things that you are thankful for today. ${ }^{6}$

c. Engage social supports, mentors, involvement in positive, recovery-oriented groups i.e.:AA/NA, Church, volunteer, affinity groups, school.

a. Service, volunteering, and a regular spiritual practice that can include prayer, meditation and reflection on inspiring literature.

b. Mindfulness, meditation has been shown to increase coping, reflection and emotional experience while reducing reactivity. ${ }^{8}$

a. Meaning making cannot occur without developing a personal narration, or lifestory that integrates all of one's experiences (i.e.: addiction, trauma, disadvantage, limits and loss along with opportunities, abilities, strengths and aspirations). ${ }^{9}$ 


\section{Discussion}

The application of Positive Psychology to the field of addiction prevention, assessment and treatment is a relatively new endeavor. This paper attempts to further the goal by demonstrating the efficacy of $\mathrm{PP}$ in addiction recovery.

PP is about identifying and living a fuller life. Recovery literature ${ }^{14-16}$ supports the building of a more enriching, meaningful and engaged life as a path to healing. PP offers an important voice in the recovery movement, a non-pathologizing and affirming theory that honestly addresses pain and suffering while providing practical strategies that guide a person to build increasing mastery in their personal lives.

The research in the PP addiction recovery field is not significant. Several studies were identified that demonstrate the efficacy of PP in working with addiction recovery. The research demonstrates that improving "positive effect, optimism, hopefulness, emotional vitality, enjoyment of life predicts favorable outcomes in cases of heart disease, stroke and general morality". ${ }^{2}$ Resilience was a core trait of participants in the study by Mohatt, Rasmus, Thomas, Allen, Hazel, \& Marlat. ${ }^{7}$ Their study ${ }^{7}$ highlights that change is unique to each person and often occurs after reflecting on consequences and the level of satisfaction with their lives, making intentional experiments with sobriety and learning from each relapse, and finally learning to rebuild a life outside of substance use, a theme common in PP. Seligman ${ }^{9}$ demonstrated the importance of optimism in the treatment of depression and Herrenkohl found that resilient children were marked by "positive self-esteem, ego-resilience, personal agency, low reactivity, high sociability, maintaining supportive relationships and gaining access to prosocial mentors; both individual characteristics and environmental influences". ${ }^{10}$

This paper discussed the PP model applied to addiction recovery. PP is a non-pathologizing model that compassionately engages a person where they are at, works to identify and enhance strengths, and to build a life apart from substance use. PP is not a "Pollyanna" model that ignores struggles or difficult diagnoses. Rather, it seeks to work with any diagnoses by broadening and building one's life. ${ }^{12} \mathrm{PP}$ also works with spiritual traditions as many of these enhance character strengths and virtues, which aid in addiction recovery. ${ }^{17-21}$

A number of practical strategies were also discussed in the paper. Far from being exhaustive, this paper illustrates a number of strategies that can be applied to the addiction field. Readers are recommended to read the excellent paper by Krentzman ${ }^{2}$ as she highlights numerous PP strategies.

\section{Acknowledgements}

None.

\section{Conflict of interest}

The author declares no conflict of interest.

\section{References}

1. David E Leininger. As we believe, so we behave: Living the Apostle's Creed. USA: CSS Publishing Company; 2009. 138 p.
2. Krentzman AR. Review of the application of positive psychology to substance use, addiction and recovery research. Psychol Addict Behav. 2013;27(1):151-165.

3. Schrank B, Brownell T, Tylee A, et al. Positive Psychology: An approach to supporting recovery in mental illness. East Asian Arch Psychiatry. 2014;24(3):95-103.

4. Lopez SJ, Gallagher MW. A case for positive psychology. In: Lopez SJ \& Snyder CR, Editors. Oxford Handbook of positive psychology. New York: Oxford University Press; 2009. p. 1-6.

5. Seligman MEP. Positive psychology, positive prevention and positive therapy. In: Snyder CR \& Lopez SJ, editors. Handbook of positive psychology. USA: Oxford University Press; 2001. p. 3-9.

6. Miriam Akhtar, Ilona Boniwell. Applying positive psychology to alcohol-misusing adolescents: A group intervention. Groupwork. 2010;20(3):1-31.

7. Mohatt GV, Rasmus SM, Thomas L, et al. Risk, resilience, and natural recovery: A model of recovery from alcohol abuse for Alaska Natives. Addiction. 2007;103(2):205-215.

8. Alim TN, Lawson WB, Feder A, et al. Resilience to meet the challenge of addiction: Psychobiology and Clinical Considerations. Alcohol Res. 2012;34(4):506-515.

9. Martin EP Seligman. Flourish. Simon \& Schuster, New York, USA; 2012. 368 p.

10. Herrenkohl TI. Person-Environment interactions and the shaping of resilience. Trauma Violence Abuse. 2013;14(3):191-194.

11. Wong LCJ, Thompson GR, Wong PTP. The positive psychology of meaning and addiction recovery. Alabama: Purpose Research. 2013.

12. Cohn MA, Fredrickson BL. Positive emotions. In: Lopez SJ, Snyder CR, editors. Oxford Handbook of positive psychology. New York: Oxford University Press; 2009. 13 p.

13. Michael Ungar (ND). Child and youth resilience interview guide. 2014.

14. Gorski T. Adolescent relapse prevention workbook: A brief strategic approach. India: Herald House/Independent Press; 1991.

15. Charlene Steen. The relapse prevention workbook for youth in treatment. USA: The Safer Society Press; 1993.

16. Sarah Bowen, Neha Chawla, G Alan Marlatt. Mindfulness based relapse prevention for addictive behaviours: A clinician's guide. New York: The Guildford Press; 2010. 179 p.

17. Jean Clinton. Resilience and recovery. International Journal of Children's Spirituality. 2008;13(3):213-222.

18. Corey LM Keyes. Toward a science of mental health. In: Lopez SJ, Snyder CR, editors. Oxford Handbook of positive psychology. 2nd ed. New York: Oxford University Press; 2009. 89 p.

19. Masten AS, Obradovic J. Disaster preparation and recovery: Lessons from research on resilience in human development. Ecology and Society. 2008;13(1):9.

20. Moriarty H, Stubbe M, Tapper S, et al. Exploring resilience in families living with addiction. J Prim Health Care. 2011;3(3):210-217.

21. Michael Ungar. Resilience across cultures. British Journal of Social Work. 2008;38(2):218-235. 